\title{
Functional roles of lipids in make-up products
}

\author{
Hélène de Clermont-Gallerande* \\ Chanel Parfums Beauté, Recherche Beauté et Innovation, 8, Rue du Cheval Blanc, 93500 Pantin, France
}

Received 10 April 2020 - Accepted 4 June 2020

\begin{abstract}
Lipids are widely used in cosmetics regardless of intended application: skincare, make-up, toiletries. If they are found in all products, it is because they have many beneficial properties for the skin. A lipid is a nourishing ingredient, a penetration vector and an emollient agent all at the same time, hence, when a finished product contains lipids it allows its manufacturer to make various claims in terms of biological activity. In addition to their well-known efficacy that is often widely promoted in conferences and in scientific journals, lipids also have a structural and functional role in formulations. This is mainly what is used in makeup. Indeed, make-up products often highlight immediate performance such as brightness, matt effect, intensity of color, sumptuous consistency or length of time the make-up stays in place, but boast few results related to biological activity demonstrated in the long term such as antiageing, repair of the skin's barrier, control of acne if we are talking about vitamin A ... Thus, the functional role of lipids being as great as their role of active ingredient, this publication aims to bring them out of the shadows and comprehensively set forth all the properties used in cosmetics. This article focuses on makeup products and on the lipids used in each of the textures. The reasons for which these lipids are present are detailed. The functions of each within different make-up preparations are reviewed. Particular attention is paid to the new raw materials - or the old ones that are coming back into fashion - in the current context of eco-design formulations. Thus, we do not elaborate greatly on mineral waxes, ozokerite wax, paraffins, and petroleum jellies, since these are not the raw materials of the future. Changes in consumption patterns are driving formulators to replace controversial ingredients with raw materials that do not engender bad press and that have a lesser impact on the environment. We present the development of the lipids used in make-up product formulations together with the impact of the same on product performance.
\end{abstract}

Keywords: clean-beauty / formulation / lipsticks / powders / foundations / mascaras

Résumé - Rôles fonctionnels des lipides dans les produits de maquillage. Les lipides sont largement utilisés en cosmétiques quelles que soient les applications : soin, maquillage, toiletries. Si on les retrouve dans l'ensemble des produits, c'est qu'ils ont de nombreuses propriétés bénéfiques pour la peau. Au-delà de leur efficacité bien connue et souvent largement mise en avant, les lipides ont aussi un rôle structurel et fonctionnel dans les formulations. C'est principalement ce qui est utilisé en maquillage. En effet, les produits de maquillage mettent souvent en avant des performances immédiates telles que la brillance, la matité, l'intensité de la teinte, la sensorialité de la formule ou la tenue mais revendiquent peu de résultats liés à une activité biologique prouvée sur le long terme. Aussi, le rôle fonctionnel des lipides étant aussi noble que celui d'actif, cette publication vise à les sortir de l'ombre et à exposer de façon exhaustive l'ensemble des propriétés utilisées en cosmétique. Cet article se concentre sur les produits de maquillage et sur les lipides utilisés au sein de chacune des textures. Les raisons pour lesquelles ces lipides sont présents sont détaillées. La fonctionnalité de chacun au sein des différentes galéniques de maquillage est passée en revue. Une attention particulière est portée sur les nouvelles matières premières - ou les anciennes qui reviennent au goût du jour - dans le contexte actuel d'éco-conception des formulations. Aussi, les cires minérales, ozokérites, les paraffines, les vaselines ne seront pas particulièrement développées puisqu'il ne s'agit pas des matières premières du futur. Les changements dans les modes de

\footnotetext{
H) Contribution to the Topical Issue "Lipids and Cosmetics / Lipides

et cosmétiques".

*Correspondence: helene.declermontgallerande@chanel.com
} 
consommation conduit les formulateurs à remplacer les ingrédients controversés par des matières premières sans risque médiatique et avec un impact moindre sur l'environnement. Une évolution des lipides intégrés dans les formulations de produits de maquillage est présentée ainsi que les impacts sur les performances des produits.

Mots clés : formulations de nettoyage / rouges à lèvres / poudres / fonds de teint / mascaras

\section{Introduction}

Lipids represent around $70 \%$ of the raw materials (Bonnet, 2018) used in cosmetic emulsions which account for the bulk of care and make-up products. That does not mean that lipids make up $70 \%$ of the ingredients in cosmetic formulations, because water remains the main component. Having said that, lipids are very important ingredients, not only because they make up a large proportion of cosmetic formulations, but also because of the role that they play in achieving the very structure of the products and their performance.

This article concerns the functional properties that lipids bring to makeup formulations such as the formation of the product and resistance to breakage. It also shows how lipids improve performance in terms of effectiveness and makeup result. The biological effectiveness of lipids shall not be discussed, as there are numerous publications on this subject, while there has been much less work done on describing the functional properties of lipids. Furthermore, it is surprising that when discussing the biological activity of a lipid in a formula, the focus is on a few percent at best, while when discussing the structure of a product or the formation of a cosmetic (lipstick, powder, mascara, etc.), $20 \%$ or even $90 \%$ of the formulation is covered. Thus, while the functional properties have fewer noble claims to make than the biological properties, they represent a significant amount of economic potential. The lipid components of lipsticks, powders, foundations and mascaras will be explained. The formulators have two chemical forms of lipids at their disposal: hydrocarbons and silicones. These lipid raw materials exist in five formats: oils, waxes, butters powders and gels. Over the last five years, launches of makeup products claiming to be made from "natural" raw materials have increased by $75 \%$ (Goodsitt, 2019). This is due to the increase in the demand for "Clean Beauty" by consumers and associated digital applications.

The Clean Beauty movement emerged in 2015, two years after a list of toxic or dangerous products present in cosmetics was published by the magazine "UFC-Que choisir" (Humbert, 2013). This movement brought about the "Clean Label" concept, which refers to consumption moving towards more natural products, while meeting the needs of consumers in terms of trust, transparency and values. "Clean Label" is responding to current expectations particularly by reducing the number of ingredients used and by replacing synthetic ingredients or by products of the oil industry with natural products (Le Mélinaire, 2019).

Alongside this trend, since 2017 consumers have had access to product rating applications, mainly via smartphones. By scanning the product or searching for it, these applications allow them to find out the composition of a product, information on each ingredient in it and similar alternatives that are judged to be better. This enables consumers to access simply and quickly an overview of the product that they want to buy in terms of its real or potential impact on their health or on the environment. These applications have been developed particularly in the cosmetics sector, but also exist for food and agricultural products and pharmaceutical products. The applications in the cosmetics sector include INCI Beauty, QuelCosmetic, Yuka, CosmEthics, Clean Beauty, etc.

The use of these applications is constantly growing, particularly for consumers who are becoming increasingly concerned and exacting regarding the composition of the products that they buy. According to a survey conducted by Statista (Moyou, 2018) on 1022 women in 2017, 58\% of them pay attention to ingredients and composition, compared with $24 \%$ who pay attention to the reputation of the brand.

Numerous brands are therefore reviewing their formulations and how they source their ingredients in order to replace the molecules derived from oil and synthetics with ingredients sourced from natural, plant or biomass origin. This will improve the ratings given to their products on the different applications mentioned above and will reassure consumers.

Finally, for each product studied, the impact of the removal of controversial ingredients on the functional properties and the performance of lipsticks, powders, foundations and mascaras is discussed. The need for raw materials to replace the oil-derived ingredients is highlighted.

All the following examples of formulations are established based on traditional compositions with no specific qualities or makeup result. The pigments, pearlescent particles, powdered fillers (unless they are composed of lipids) and components of the aqueous phase are non-lipid raw materials, and are not described in the same way which is also the case for the lipid ingredients that are biologically active, such as ceramides, sun filters, etc.

\section{Roles of lipids in lipsticks}

\subsection{Composition}

Lipstick is an anhydrous product. It is composed of oils, waxes, butters, polymers, gels and antioxidants. Some of them are unavoidable, such as waxes and oils, while others are optional, such as silicone elastomers and oil gelling agents. They include a mix of carbon or silicone-based raw materials. The carbon-based raw materials are of plant or synthetic origin or are oil by products such as certain waxes. Silicone-based raw materials can be volatile or can be non-volatile if a product with long-lasting hold is desired (Tab. 1).

As lipstick is an anhydrous product consisting solely of fats, they supply not only its functional properties but also the claims relating to the effectiveness of the product, obviously excluding any specific active ingredient. The pigments and other non-lipid components, which are obviously present in makeup, are not covered, only the lipids are described. 
Table 1. Lipids in the composition of lipsticks.

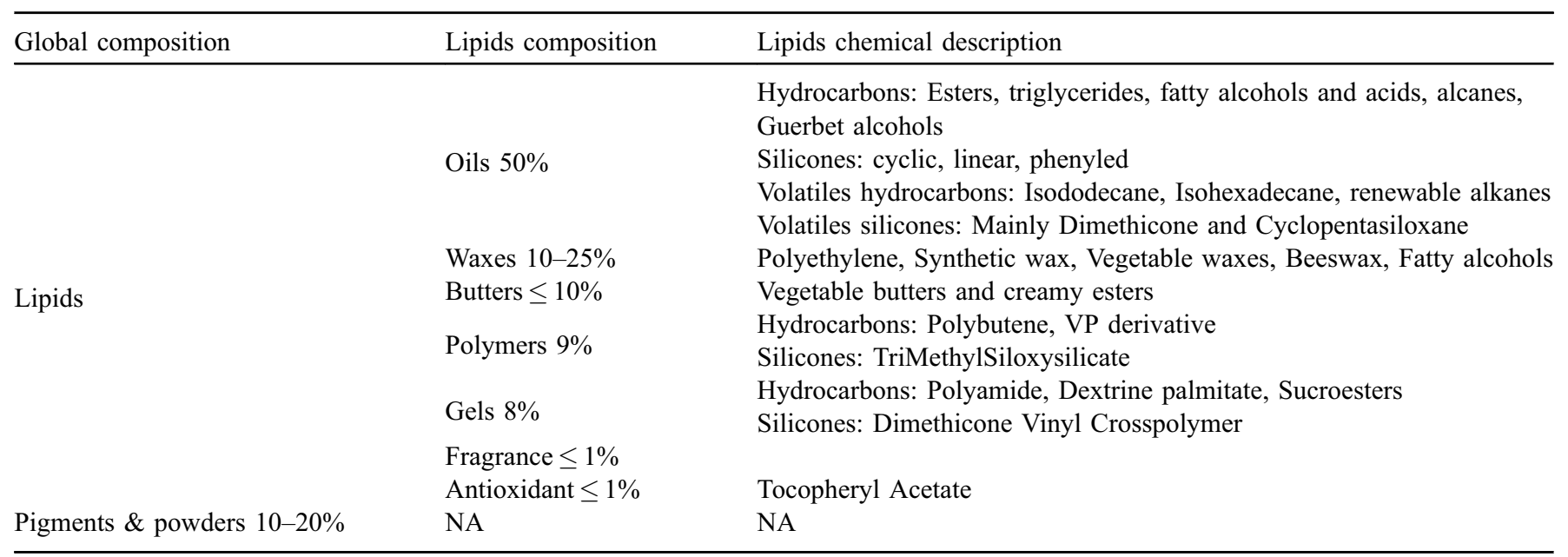

\subsection{Technical assets linked to the functional properties of fats in lipsticks}

Structure in stick form: This might seem obvious, but it is nevertheless helpful to repeat it: waxes are vital for giving lipsticks their final shape. They enable a hot liquid paste to be poured into a mould in the form of a stick. This liquid becomes solid at room temperature, which creates the lipstick. Waxes enable oils to gel and allow moulding but also facilitate removal from the mould since they shrink as they cool. The property of facilitating removal from the mould is particularly true for waxes which are by products of the oil industry: Ozokerite, Synthetic wax and Polyethylene wax. They thus help to give the hard quality that enables it to be formed and used. A woman exerts a force of $500 \mathrm{~N}$ to $600 \mathrm{~N}$ when putting on her lipstick (De Carames, 1978; Drew, 1978). The lipstick should not therefore break on its first application. The lipstick needs to both be able to be moulded and removed from its mould easily when in production and provide resistance to breakage when being applied by the customer.

Heat resistance: The raw materials that retain the shape of the stick at temperatures above $30^{\circ} \mathrm{C}$ are the waxes and gelling agents. Their role is to ensure that a lipstick is heat resistant above $50^{\circ} \mathrm{C}$, a temperature that can be reached relatively quickly, and does not spuriously melt into a waxy, coloured liquid. Dropping point tests are therefore carried out on lipsticks in order to ensure that the first drop does not fall until it reaches a temperature of above $50{ }^{\circ} \mathrm{C}$.

Resistance to thermal shocks: The phenomenon of exudation involves the appearance of fine droplets of oil on the surface of a lipstick (Dweck, 1981). Although this is harmless, the droplets give the appearance that the quality of the product has deteriorated, which is incompatible with the image of reliability and perfection that a luxury brand wishes to convey. It has therefore been shown that the polymorphism of certain butters whose melting range is between 25 and $50^{\circ} \mathrm{C}$ could be the cause of the appearance of these undesirable droplets (Snabre and Habouzit, 2013). When the lipstick is exposed to a series of thermal variations such as successive cycles of hot and cold, then the exudation appears, then disappears and

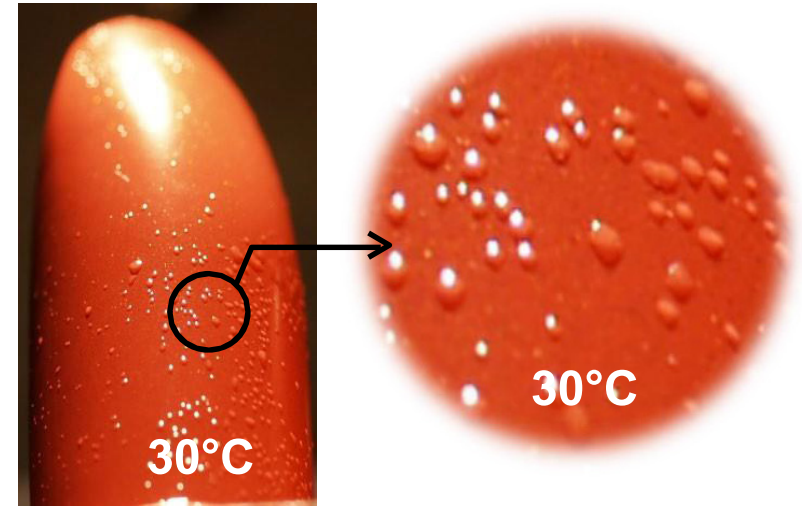

Fig. 1. Exsudation of a lipstick after exposure to $30^{\circ} \mathrm{C}$.

reappears continuously (Fig. 1). The functional role of lipids is to provide stability to the formulation in the context of temperature variations. Waxes and butters contribute to the stability of the sticks when exposed to shocks and influence the phenomenon of exudation. Their impact may be positive or negative, as is often the case with polymorphic butters. Conversely, as they are not polymorphic, synthetic waxes, ozokerites and polyethylene waxes are very useful raw materials for preventing the phenomenon of exudation. Vegetable waxes such as carnauba and candelilla wax do not give the matrix of the stick the necessary elasticity to absorb the excessive pressure created when the butters melt at low melting points. They do not allow the surplus of liquid that appears with the rising temperature to which the lipstick is exposed to be absorbed, thus causing the oil to be expelled onto the surface of the stick and creating exudation (Kermarec, 2011).

Role of solvents: oils, waxes, polymers, gelling agents and active ingredients must be perfectly miscible with each other. If this is not the case or if the process is not sufficiently controlled (Nandkishor et al., 2019), crystallisation phenomena may appear (Fig. 2). 


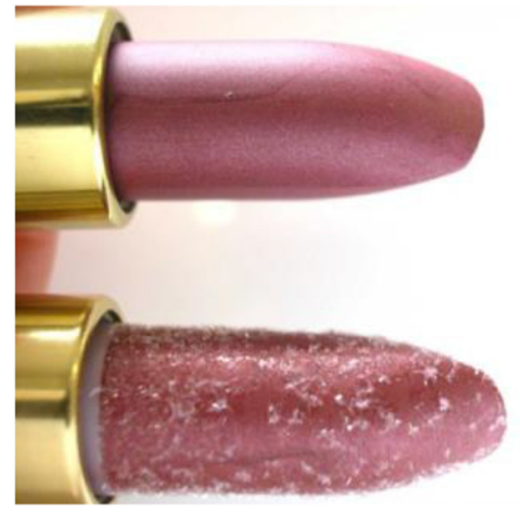

Fig. 2. Crystallisation obtained by the incorporation of 5\% of Butyl Methoxydibenzoylmethane fat-soluble sun filter.

Role of oxidative stability: a product such as a lipstick which is solely composed of lipid raw materials is inevitably subject to oxidation. This is even more the case given that by moving towards natural formulations in order to respond to the demand for "clean beauty", more and more raw materials are being used that contain unsaturated lipids. These are easier to oxidise than synthetic raw materials. The risk is even greater when the shade contains pigments such as metallic oxides. Lipstick is applied to the mouth and therefore under the nose: it is tasted and smelt. A lipstick with a rancid smell and taste is unacceptable to consumers. Tocopheryl Acetate is the only antioxidant currently available.

\subsection{Makeup result linked to the functional properties of fats in lipsticks}

Transparency: One of the requests that marketing may make to the R\&D laboratories is to formulate visually transparent sticks. This is achieved by replacing the waxes traditionally used to structure lipsticks (de Clermont-Gallerande et al., 1999). Some lipophilic gelling agents used to replace waxes produce transparent sticks (de ClermontGallerande, 2001). These gelling agents include some grades of dextrin palmitate, polyamide and sucrose esters.

Slipperiness: As Figure 3 shows, the viscosity of the oils (or the blend of oils) incorporated into the formulation directly correlates with the "slipperiness" descriptor measured during sensorial analysis (Douguet et al., 2017; Abidh, 2019).

Glossy/Matt finish: There is an excellent correlation between the glossiness of oils and their refractive index (Fig. 4). The higher the refractive index of an oil, the glossier it is. Therefore, the level of gloss or matt finish of a lipstick is directly linked to the physical and chemical qualities of the oils used in the formulation.

Silicones provide a great deal of shine, mainly the Phenyl Trimethicone. In addition, unlike Polybutene, which is also very glossy, Phenyl Trimethicone, a lubricating silicone, gives shine to formulations without adding any stickiness (de Clermont-Gallerande et al., 2018).

Hold: Hold is something that consumers inevitably expect. The requirements are increasingly high: makeup result holding for $12 \mathrm{~h}, 16 \mathrm{~h} .$. Preserving your lipstick after a meal is difficult, and after 2 meals it is quite a feat. The raw materials that

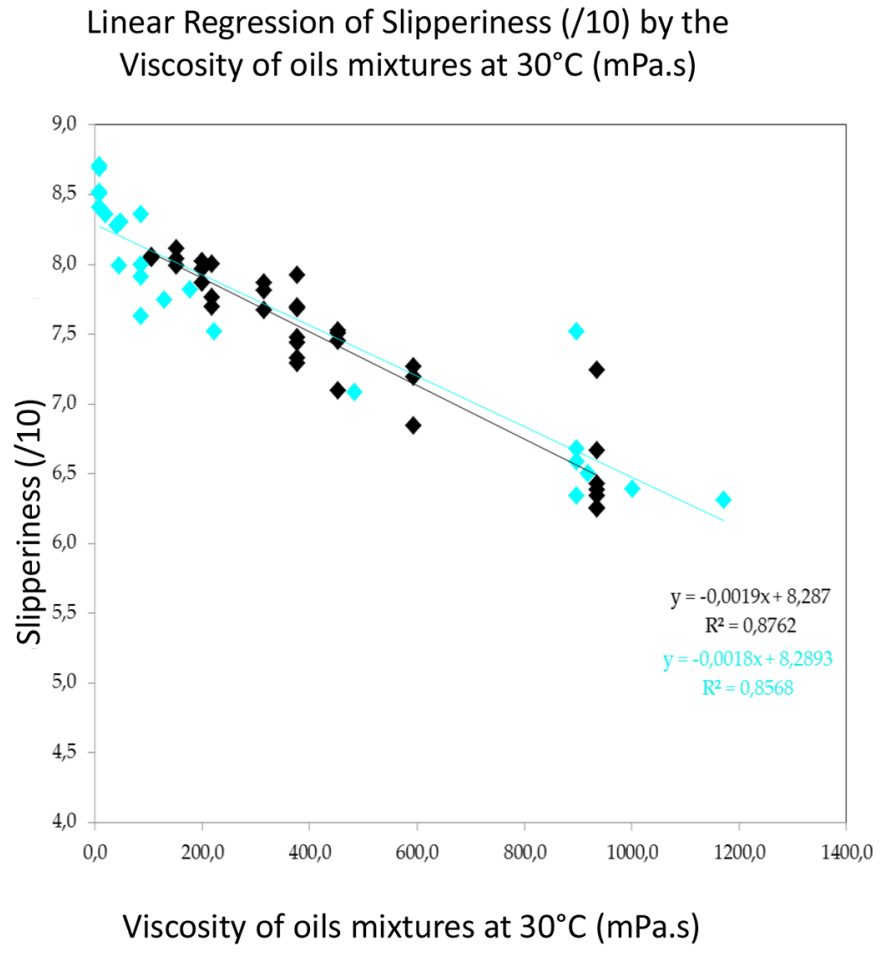

Fig. 3. Linear regression analysis of Slipperiness (/10) by the Viscosity of oils mixtures at $30^{\circ} \mathrm{C}(\mathrm{mPa} . \mathrm{s})\left(\mathrm{R}^{2}=0.8762\right)$.

promote hold are polymers, Polybutene and silicone resins such as Trimethylsiloxysilicate plasticised using Dimethicone.

Non-transfer: It is possible to go even further with the claim of long-lasting lipstick with a no-transfer claim. In this case, no trace of lipstick must be left on a glass, clothes, etc. after contact between the surface and the made-up mouth (Fig. 5). In formulation, achieving this performance requires incorporating volatile oils into the formulation as well as the polymers already mentioned above for hold. They will therefore contain volatile carbon oils such as Isododecane or Isohexadecane or volatile silicone oils such as Cyclopentasiloxane and low viscosity dimethicones.

Hydration: Lipsticks are anhydrous and occlusive, which means they can claim a measured level of hydration. One of the properties of fat is therefore hydration, which is also called emollience for this type of product. Moreover, the occlusivity of fats leads to a reduction in trans epidermal water loss (TEWL). The effects of hydration are that the softness and suppleness of the lips is maintained, the elasticity of the skin is improved (Loubat-Bouleuc, 2004), there is no chapping or wrinkles and it can even result in plumping or expansion of the lips.

\section{Roles of lipids in powders}

\subsection{Composition}

The presence of lipids is much less evident in powder formulations than in lipstick formulations. Nevertheless, the functionality of lipids is expressed in these products as much as in cream makeup products. Without the specific properties of the lipids, the powders could not be formulated. There are 


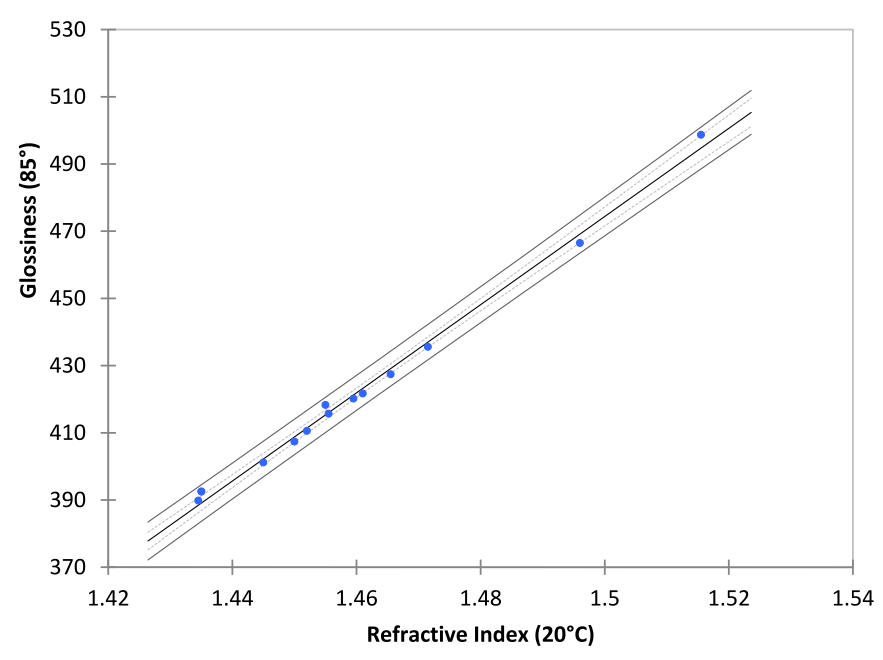

\begin{tabular}{l}
\hline Modèle(Glossiness (85 $\left.5^{\circ}\right)$ Int. de conf. (Moyenne 95\%) \\
Int. de conf. (Obs 95\%)
\end{tabular}

Fig. 4. Linear regression analysis of Glossiness (Samba at $85^{\circ}$ angle) as a function of the Refractive Index $\left(20^{\circ} \mathrm{C}\right)\left(\mathrm{R}^{2}=0.995\right)$.

several varieties of makeup: poured cream makeup is close to lipstick and will not therefore be covered. There are also numerous methods of manufacturing powders, and therefore different formulations depending on the technology chosen. Compact makeup is traditional makeup presented in pans. These are the ones detailed below (Tab. 2).

These are anhydrous, powdered products, which are largely composed of mineral fillers or coloured raw materials (pearlescent particles, pigments) which will not be discussed. Within the powdered phase, surprisingly there are lipids. Among the lipid powdered fillers there are silicone beads, microplastic beads and Lauroyl Lysine, a lipid powders with plate-like particles, in certain formulations. In the powdered phase, there are also compacting agents, which are powders which facilitate pressing and the cohesiveness of all the powdered fillers. These powders are strategic in the formation of the product. There are low percentages of compacting agents $(1$ to $5 \%)$ in powders that are compressed flat. The percentage may increase to 20 or $25 \%$ if the powder is shaped, for example in a dome shape, or if the diameter of the pan is very wide (more than $6 \mathrm{~cm}$ ). To compress the powders, a fatty binding agent is incorporated into the formula. This creates bonds between the powdered fillers and facilitates pressing.

\subsection{Technical assets linked to the functional properties of fats in powders}

Cohesivity: Compacting agents must provide the necessary cohesivity to the product while preserving a degree of suppleness of the compressed solid product. Powdered compacting agents are most influential in this respect. These include metallic salts such as Magnesium Stearate and Magnesium Myristate. These are unavoidable agents. As well as facilitating compacting, metallic soaps are also raw materials that prevent the powder from clogging during

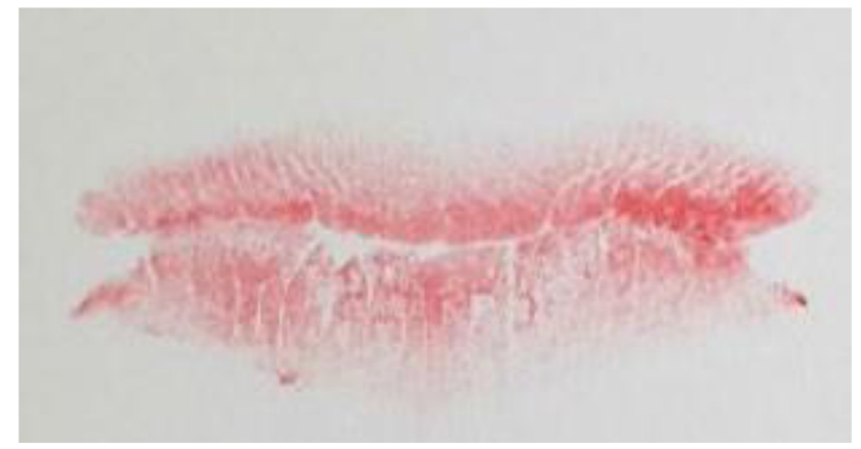

Fig. 5. Evaluation of the degree of transferability of a lipstick formulation onto a white medium.

manufacture or storage. They are therefore precious allies. Their percentage is often increased when the powder is shaped in order to prevent products from breaking or cracking. Micronized wax beads are also excellent compacting agents. The most frequently used type are Polyethylene wax beads, but environmental protection regulations have sounded the death knell for their use. The ratio between spherical and flaky particles is equally important for achieving a cohesive powder. Spherical lipid powders include plastic and polyethylene microbeads and silicone beads. There are few flaky lipid powders. The most well-known currently is Lauroyl Lysine. The overall balance of the formulation is to obtain a highquality compact powder: the ratios between spherical and flaky powders and the ratio between the quantity of the powdered phase and of the oily liquid phase are the parameters that determine the cohesivity of the compact powder (de ClermontGallerande et al., 2014).

Resistance to breakage: Each product must resist a repeated drop test (in general three consecutive drops from a height of $30 \mathrm{~cm}$ onto a metal medium) without breaking. This is supposed to prevent any breakage of the product. If it is a luxury brand product, its purchase price is sometimes significant. The aim is to prevent a clumsy client who drops her new compact powder in her bathroom from finding it broken into a thousand pieces... There are various powdered compacting agents. They include Polyethylene microbeads, micronized Carnauba wax beads, Glyceryl Behenate or metallic soaps such as Magnesium Stearate. They make the powder cohesive and prevent the product from breaking as soon as it is dropped (Fig. 6). Their percentage is often increased when the powder is shaped order to prevent the powder from being too fragile. In the same way, the fatty binding agent, which creates bridges between the grains of powder, helps the cohesion of the product and reduces the risks of breakage.

Compactibility: this property is the ease of formation of a powder by pressing in an industrial context. The surface of the compact powder obtained after the formation process must be homogenous, smooth and free of cracks in order to be easily compactable (Tita-Goldstein, 2013). Essential for the formation of the product, compactibility is mainly ensured by the fatty binding agent. It must enable the powder to be compacted without the surface becoming shiny and without it becoming so 
Table 2. Lipids in the composition of powders.

\begin{tabular}{lll}
\hline Global composition & Lipids composition & Lipids chemical description \\
\hline & & Silicone beads, Microplastic beads \\
& Lauroyl lysine \\
Powders including pigments & Powders $+/-90 \%$ & $\begin{array}{l}\text { Polyethylene beads, Micronized vegetable waxes, Glyceryl Behenate, Montan Wax } \\
\text { Metallic soaps: Mg/Zn Stearate, Mg Myristate }\end{array}$ \\
& Preservatives $\leq 1 \%$ & Lipoaminoacids \\
& Oils 2 to $20 \%$ & Hydrocarbons: Esters, Squalane, Vegetable oils \\
Siquid binder & Antioxidant $\leq 1 \%$ & Tocopheryl Acetate \\
& Fragrance $\leq 1 \%$ & NA \\
\hline
\end{tabular}

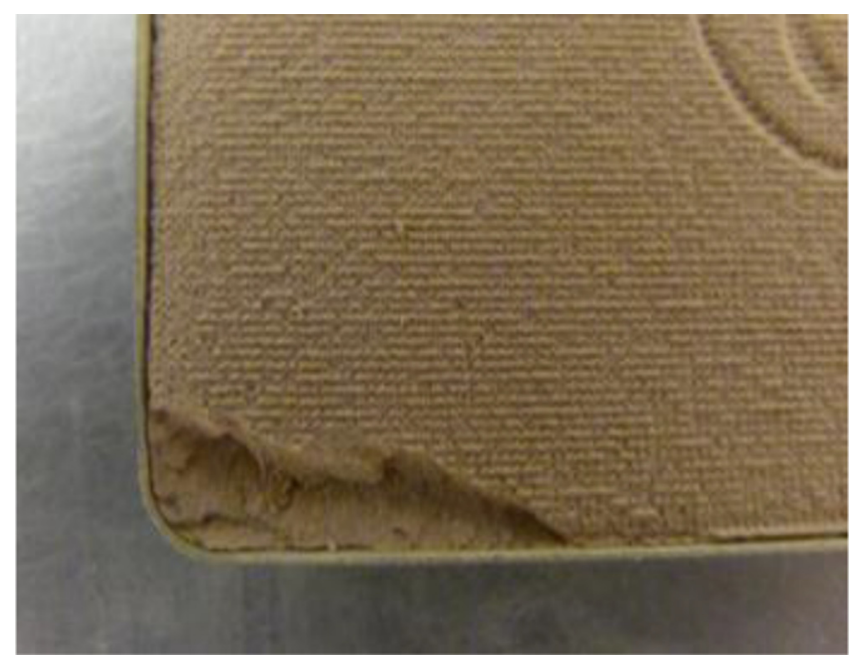

Fig. 6. Non-compliant compact powder after drop test.

compact that it is impossible to continue to use it. Conversely, a badly dosed fatty binding agent leaves the powder crumbly, so it disintegrates too easily. The percentage of fatty binding agent therefore needs to be adapted according to the porosity and oil absorption capacity of the powdery fillers in the formulation. This oil or blend of oils, added in a proportion of between 3 and $10 \%$ depending on the formulation, creates a bond between all the powdery fillers and creates liquid bridges between them (Pietsch, 2002). The ester frequently found in fatty binding agents is Octyldodecyl Stearoyl Stearate (Fig. 7). Branched esters are traditionally appreciated, along with hydrocarbon oils with one or more hydroxyl functions. This function promotes the creation of liquid bridges between the molecules to optimise compacting. Liquid silicones of various viscosities are also very widely used for compacting, because they combine functional and sensory performance. In the same way as for resistance to breakage, compacting agents which facilitate the cohesion of the powder are unavoidable. These include polyethylene microbeads and metallic soaps. They are therefore precious allies. They prevent cracks in compacts and breakage when dropped as well as facilitating industrial compacting.

Clogging and vectorisation: it is important to prevent the powder from clogging, either during distribution via a hopper and a dosing system at the time of compacting into pans, or during storage. Caking of the powder is detrimental to proper compacting and does not allow a perfectly flat surface to be

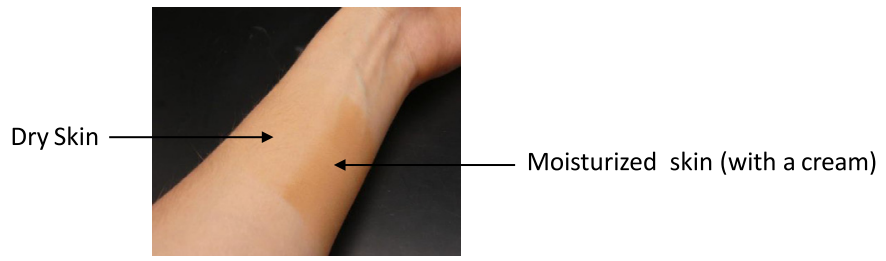

Fig. 8. Comparison of the shade of a compact powder applied to dry skin and skin that has been moisturised first.

achieved. Moreover, certain formation procedures involve vectoring powder through air (Weckerle, 2020). It is therefore imperative that the powder is not compressed at the time of injection and does not clog in the distribution circuit. Lipid raw materials that prevent clogging are silicone beads, Lauroyl Lysine and metallic soaps. The level of fatty binding agent must also remain moderate in order to preserve the fluidity of the powder.

Microbiology: Some lipoamino acids limit the proliferation of germs (Seppic, 2020b). This is the case for Undecylenoyl Glycine. These molecules are used in addition to the preservatives listed to boost the effectiveness of the preservative system.

\subsection{Makeup result linked to the functional properties of fats in powders}

Soft-focus: The blurring of wrinkles and fine lines is achieved through the microbeads in the formula. Until now, Polyethylene microbeads played this role in addition to being excellent compacting agents. It was a functional and active ingredient at the same time. The banning of these beads has passed this role onto the small diameter spherical mineral fillers such as cellulose or silica beads. In terms of lipid beads, there are Montan wax beads, Carnauba wax beads and Glyceryl Behenate beads. However, while these natural wax beads do play the functional role of compacting agent, none of them has the sensory or soft-focus performance of polyethylene microbeads. The latter have the property of reflecting light in a diffused way, which reduces the appearance of wrinkles and fine lines and mattifies the skin. Conversely, the mineral fillers with plate-like particles in the formula reflect the light like a mirror, and therefore perpendicular to the incident light, which provides gloss. In most cases, a matt finish is 


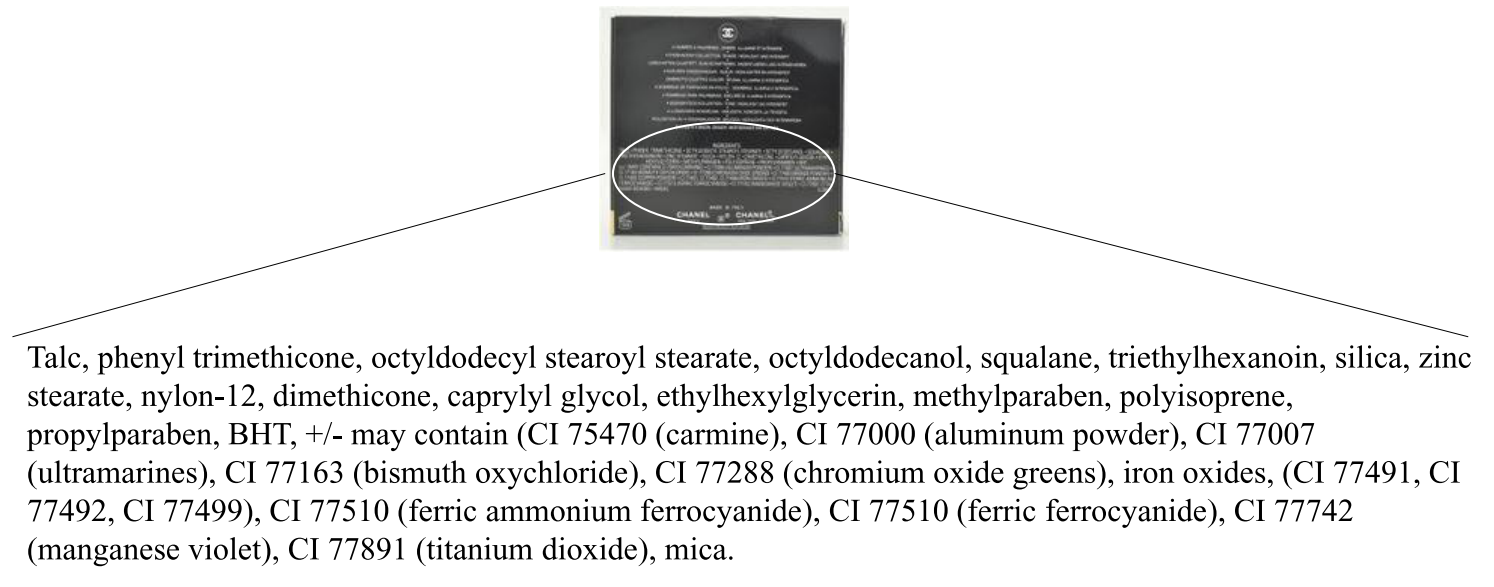

Les 4 Ombres multi-effets Quadra eyeshadows Noir et Blanc de Chanel Collection Fall 2019

Fig. 7. Exemple of eyeshadows ingredient list in INCI names. The fatty binding agent contains Octyledodecyl Stearoyl Stearate and Dimethicone. INCI: International Nomenclature of Cosmetic Ingredient.

sought in compact powders. Micronized wax beads are therefore compacting agents, anti-clogging agents, but also active ingredients for the soft-focus effect and matt finish.

Slipperiness, creaminess and ease of application: Lauroyl Lysine is a flaky powdered white lipid filler introduced with the mineral powders in the formulation. The powdered fillers may comprise up to $95 \%$ of the total composition. Lauroyl Lysine only represents a small proportion: $10 \%$ at most. It provides a creamy feeling, softness, transparency and slipperiness to powders (Ajinomoto, 2017). It is a greasy powder, which is unexpected for this type of raw material (Oshimura, 2016). Its lubricating qualities are a technical advantage for this type of product. Despite being exceptionally soft, this powder has a defect. Bacteria really like its composition and it is very difficult to preserve a powder that contains Lauroyl Lysine. Conversely, metallic soaps have a dry feel, and will soon slow down application because they are not slippery. They do not therefore foster the 3 sensory criteria. Silicones incorporated alone or as a blend into the fatty binding agent play a major role in homogeneous application onto the skin. Liquid dimethicone coupled with silicone beads in the powdered phase or even with silicone elastomers in the fatty binding agent, enables an optimum spreading of the formulation in terms of homogeneity and slipperiness. Customers want a uniform makeup result across the madeup area. Silicones are precious allies in trying to achieve this. To date there are no known substitutes.

Similarities between the solid shade and the shade on application: The choice of which chemical nature of fatty binding agent plays a decisive role in the correspondence between the colour of the compact powder and the colour that is visible on application. A difference perceived by the customer can be very deceptive. An increase in shade is very commonly observed and can reach Delta E values of more than 2 with mainly an increase towards orangey reds. When customers try products in a shop, their skin is not moisturised using cream beforehand, unlike what they would do during their makeup routine every morning. In fact, the powder will be applied either after a moisturising cream or after a foundation. In any case, the result is different to application on dry skin

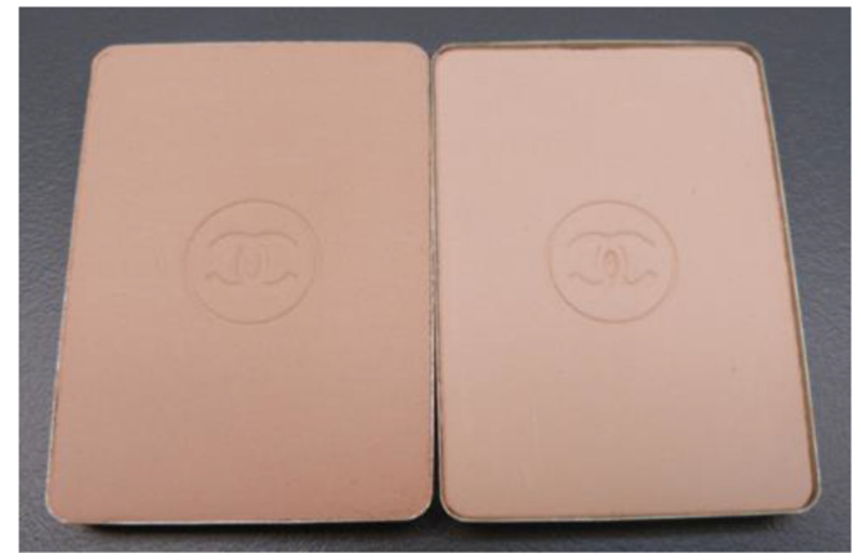

Fig. 9. Comparison of the mass tone of two compact powders with the same composition in the powder phase but a different fatty binding agent.

(Fig. 8). It is therefore vital to ensure that the increase in shade between the solid powder and the shade of the product applied onto dry skin or moisturised skin is reduced. Again, the chemical state of the fatty binding agent and the capacity for oil absorption of the porous spherical beads are parameters which play a decisive role in the similarity between the shade of the compact and the shade of the applied powder and between the shade applied onto dry or moisturised skin.

Shade intensity: The intensity of the shade of a powder is a key factor in the attractiveness of the product. A saturated colour is more flattering than a desaturated colour. Moreover, if the shade is saturated in the pan, it will become less so on application to the skin, according to the makeup yield criterion described in the paragraph above. Final colour is obtained by the pigments and the capacity of the oil phase to wet them and so to develop their saturation (Fioleau et al., 2015). Therefore, the goal of the formulator is to find the best oil phase composition in order to reduce the saturation gap between mass tone and the application. The fatty binding agent is the element that modulates the saturation of the shade of the compact powder (Fig. 9). 
Table 3. Lipids in the composition of foundations.

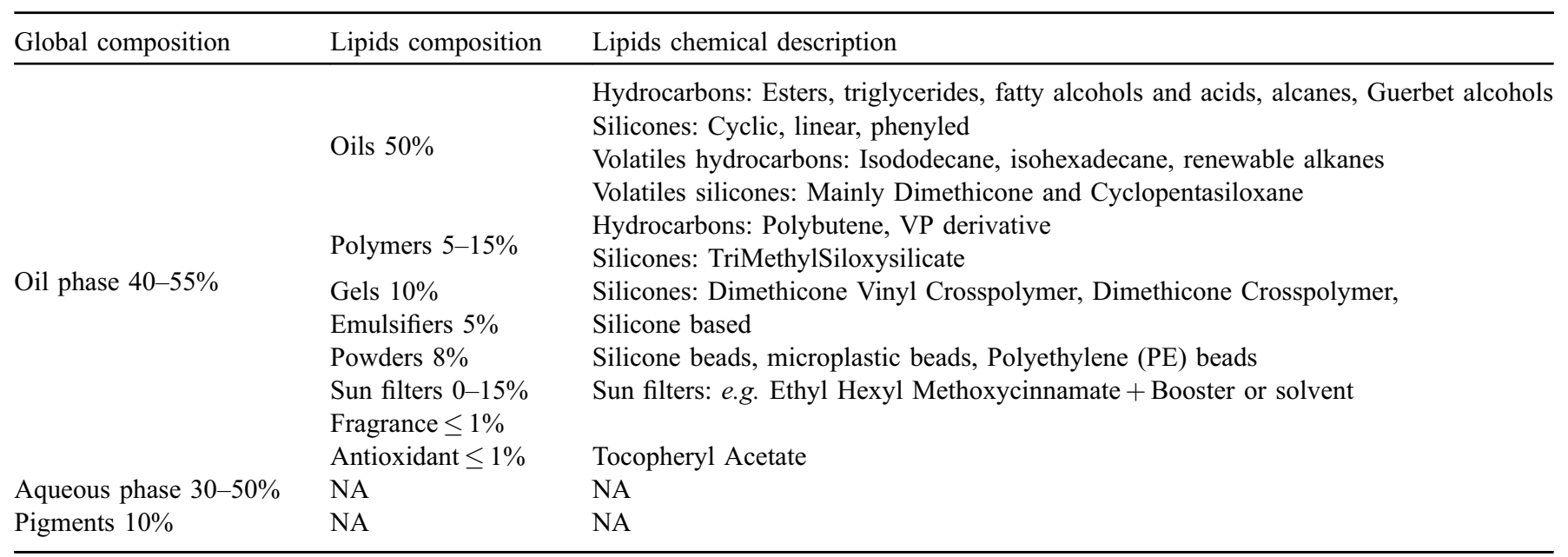

\section{Roles of lipids in foundations}

\subsection{Composition}

For more than twenty years, foundations have almost all been water-in-silicone emulsions (Tab. 3). This formulation is, however, in decline, even though the substitutions are complicated to implement without significantly affecting the performance of the makeup result. Moreover, the chemical sun filters are also in the hot seat, whereas sun protection is one of the major claims made by foundations after visual improvement of the appearance of the skin on the face. It is therefore the makeup product that is most impacted by the demand for substitution of controversial raw materials.

Water/silicone emulsions have an external silicone lipid phase. Therefore, the majority of the oils are non-volatile silicone chains which include Dimethicone, Caprylyl Methicone and Phenyltrimethicone, or volatile chains such as Cyclopentasiloxane or low-viscosity Dimethicone. The carbon oils that are present are compatible with the liquid silicones, esters and alkanes. Common volatile carbon oils are Isododecane, Isohexadecane and more recently Undecane \& Tridecane, a blend of renewable alkanes. The surfactants are also ethoxylated or polyglycerinated silicones. The viscosity control agents are in the external phase and are mainly silicone elastomers such as Dimethicone Vinyl Crosspolymer or Dimethicone Crosspolymer. For hold performance, polymers are introduced. They are silicone polymers such as the silicone resin Trimethylsiloxysilicate, or carbon polymers such as Polybutene and derivatives of Vinyl Pyrrolidone. Finally, as in all makeup products, there are powders. The lipid powders frequently found in foundations are silicone beads, and Polyethylene or plastic microbeads. As sun filters are active ingredients, they are not detailed in this article, which is only concerned with functional lipids. Water/silicone foundations do not need to be heated for manufacture as all the raw materials are liquids at room temperature. This is also more suited to these formulations, which often contain a high percentage of volatile oils.

\subsection{Technical assets linked to the functional properties of fats in foundations}

Stability: this is directly linked to the surfactant and optimised by the gelling agent, which slows down coalescence.

\subsection{Makeup result linked to the functional properties of fats in foundations}

Matt or Glowy finish: While the desired makeup result in Europe is a matt finish, this is not the case in Asia. Women prefer a shinier look, which is commonly known as glowy; the aim is not to be shiny in an oily way but to have hydrated, plumped, smooth skin, as if it is saturated with water, so that the appearance of the skin is as close as possible to that of the white of a hard-boiled egg. Oils therefore have an important role to play in the final look of the foundation on application. For a matt look, branched esters such as Isononyl Isononanoate and esters close to that molecule as well as volatile hydrocarbon or silicone solvents will be preferred. For a glowy effect, the preference will be for shorter, non-volatile, branched hydrocarbon chains, or among the silicones, Phenyltrimethicone.

Soft-focus, homogeneity on application, slipperiness: The soft-focus effect is achieved by the microbeads in the formula, because the spheres reflect the light in a blurred way. Until now, Polyethylene, Nylon and silicone microbeads played this role. They were a functional and active ingredient at the same time. The banning of these beads has passed this role onto small diameter spherical mineral fillers, such as Cellulose or Silica beads, but the latter dry out the skin. Moreover, these beads do not have the sensory qualities or the same soft-focus performance as plastic microbeads. They also do not provide the same homogeneity on application, as silicone beads or plastic beads are particularly good lubricants. They therefore result in reduced spreading performance, reduced slipperiness but also less effective camouflaging of wrinkles and fine lines. 
Table 4. Lipids in the composition of mascaras.

\begin{tabular}{|c|c|c|}
\hline Global composition & Lipids composition & Lipids chemical description \\
\hline \multirow{4}{*}{ Oil phase $30-40 \%$} & \multirow{2}{*}{ Waxes $15-20 \%$} & Beeswax \\
\hline & & Antifoaming oil: Dimethicone \\
\hline & Polymers $10 \%$ & Hydrocarbons: Polybutene, Vinyl Pyrrolidone (VP) derivatives \\
\hline & Emulsifier 5\% & Triethanolamine Stearate, Alkyl Phosphate, Potassium Alkyl Phosphate \\
\hline Pigments \& powders $10-15 \%$ & NA & NA \\
\hline
\end{tabular}

Long-lasting hold: Long-lasting hold is very much in demand for foundations. Some products claim to hold for $16 \mathrm{~h}$, and even $24 \mathrm{~h}$. If the foundation contains a volatile solvent, the solvent helps the film to hold on the face. The solvent serves as a vector for the rest of the formulation on application, but it evaporates leaving a dry, coloured film on the skin. Until now, most foundations with a long-lasting hold claim have contained volatile silicone solvents, in particular Cyclopentasiloxane or low viscosity dimethicones. The most commonly used hydrocarbon solvents are Isododecane, Isohexadecane and more recently Undecane \& Tridecane. As for lipsticks, the polymers are the raw materials that provide hold in addition to volatile solvents. Those used are the traditional Polybutene, Acrylates and derivatives of Vinyl Pyrrolidone for hydrocarbon polymers and silicone resins such as Trimethylsiloxysilicate plasticised using Dimethicone for silicone polymers.

\section{Roles of lipids in mascaras}

\subsection{Composition}

Mascaras are oil and water emulsions whose oily phase is mainly composed of waxes. The example given is a traditional mascara (Tab. 4). The specific formulation of waterproof mascaras is not presented in this publication.

Mascara is a waxy emulsion which contains between 15 and $20 \%$ wax. The specific characteristic of this product is that it contains no silicones apart from those used to avoid the introduction of air into the formula during manufacture. The waxes are therefore hydrocarbons: Beeswax, Candelilla, Carnauba and Rice wax and waxes derived from oil such as Paraffins. Polymers help adhesion onto the lash and help the mascara to stick when the brush passes over the lashes. They are also carbon-based and may comprise up to $10 \%$ of the formulation: derivatives of Vinyl Pyrrolidone, and Polybutene. As for foundations, surfactants are added in a proportion of around $5 \%$. They are hydrocarbons like the rest of the emulsion and are generally anionic soaps of Triethanolamine (TEA) or Alkyl Phosphate. An antioxidant, such as Tocopheryl Acetate, prevents the oxidation of the product.

\subsection{Technical assets linked to the functional properties of fats in mascaras}

Making the emulsion: it is complex to emulsify such a significant waxy phase. Therefore, the choice of surfactant is strategic, and soap surfactants produce stable and shiny emulsions. The soap-based emulsifying system is made up of Stearic Acid, TEA and/or Aminomethyl propanediol (AMPD), a $\mathrm{pH}$ buffer. A TEA Stearate is an anionic emulsifier, formed through the following saponification reaction:

\subsection{Stearic acid + TEA à TEA Stearate}

In fact, TEA with the formula $\mathrm{N}\left(\mathrm{CH}_{2} \mathrm{CH}_{3}\right)_{3}$ is a weak base with a bivalent cation while stearic acid is monovalent. The reaction is therefore carried out with two moles of acid to one mole of TEA. The percentage of use of TEA is limited by regulations (European Parliament and European Council, 2009). Its conditions of use are equally restricted. For these reasons, TEA may not make up more than $2.5 \%$ of a formulation. It is therefore coupled with AMPD to adjust the $\mathrm{pH}$ to that of the eye area, which is slightly above 7. Moreover, adding AMPD ensures that all the molecules of stearic acid are used up. This emulsifying system enables the formulation of mascaras that are creamy, liquid and shiny at the same time.

Generation of nitrosamines: Nitrosamine is a carcinogenic substance, which develops from amines and from a source of nitrites. In the composition of mascara amines may be supplied by TEA, the main generator of nitrosamines, but also certain active ingredients, gels, polymers (Department of Consumer and Veterinary Affairs, 2017). Nitrites may be supplied by water, packaging materials or storage conditions if the packaging or raw materials are in plastic sachets with no clarification regarding the nitrite-free specification. Amines are divided into three families: primary, secondary and tertiary amines. This division stems from the fact that the nitrogen atom may be linked to one, two or three groups other than a simple hydrogen atom. The chemical nature and size of these groups influence the reactivity of the amine. For the nitrosation reaction, it is the reaction of a nitrite (NO) group on the nitrogen $(\mathrm{N})$ function of the amine. This means that the more this nitrogen is saturated, as is the case in tri-substituted amines, the more difficult it will be for the reaction to take place. TEA is a tertiary amine. It is therefore the least reactive of the amines. AMPD is a secondary amine. This compound, which is recurrent in mascara formulations, can also be a source of development of nitrosamines. In the presence of nitrosating agents such as nitrites, nitrous acid and nitrogen oxides, amines produce nitrosamines: this is the nitrosation reaction (Fig. 10). The reaction of nitrites with TEA produces a specific nitrosamine, N-nitrosodiethanolamine (NDELA). In 


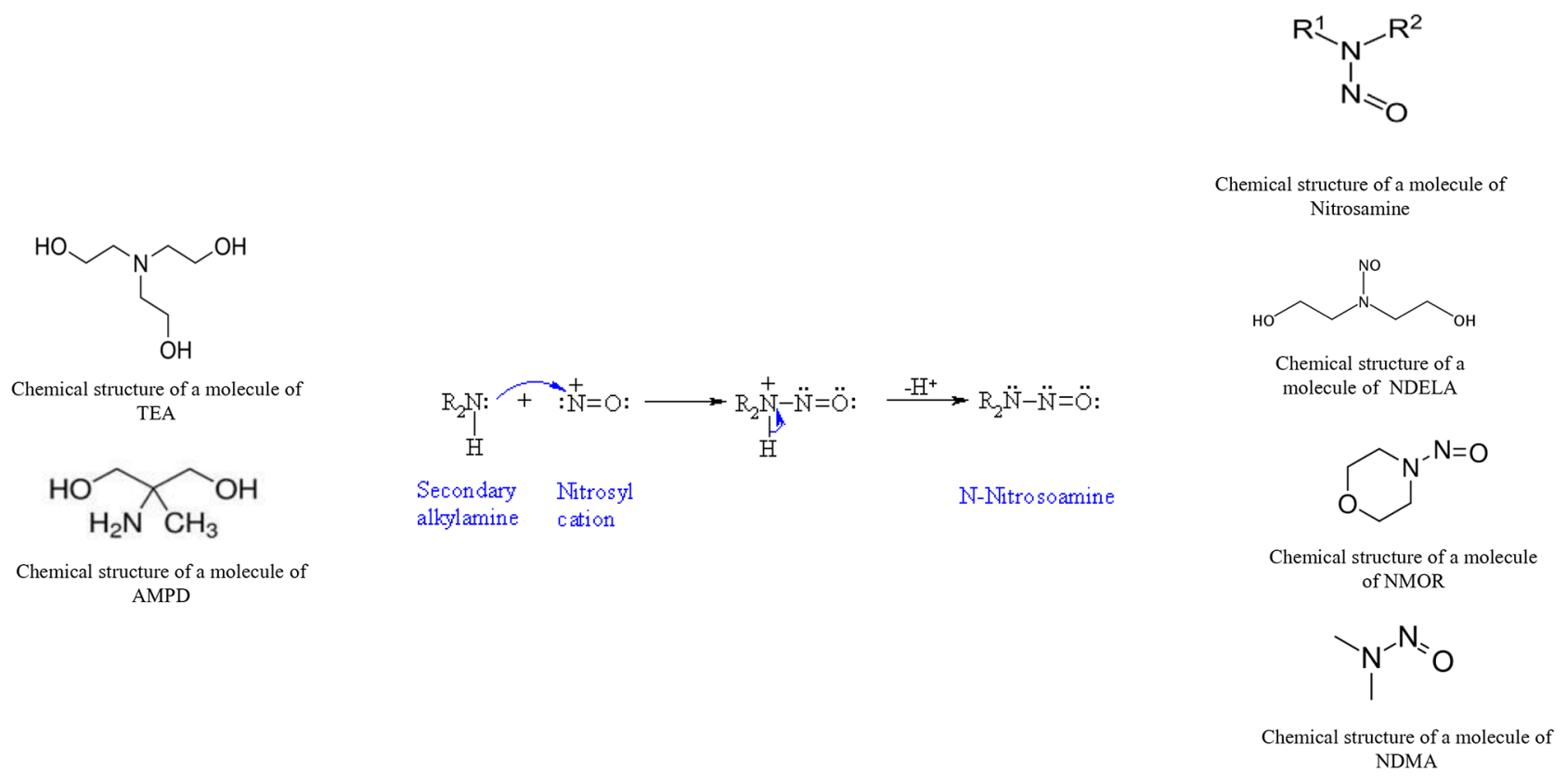

Fig. 10. Chemical structure of the molecules that are part of the nitrosation reaction and general reaction mechanism.

cosmetics, there may also be other types of amines: nitrosomorpholine (NMOR) and N-nitrosodimethylamine (NDMA).

Substituting Triethanolamine Stearate is complex. The consequences observed are the deterioration of the makeup result and a significant increase in the viscosity of the product over time.

Anti-foaming property: Mascara is a very consistent emulsion. The rheological measurements are frequently between 3000 and $90000 \mathrm{~Pa}$. It is therefore important not to introduce air into the paste when manufacturing it as it would be very difficult to subsequently deaerate such a compact formulation. Dimethicone is a very good anti-foaming agent. Equally effective non-silicone substitutes are being sought.

\subsection{Makeup result linked to the functional properties of fats in mascaras}

Volumising and lengthening effect: The volumising effect of a mascara can be characterised visually: it must thicken the lashes by increasing their diameter. A volumising mascara densifies lashes that are too sparse. The lipid raw materials that are commonly used to achieve this are waxes. In mascara formulations, the percentage of soft waxes such as Beeswax is considerable. This material coats the lash, giving it volume. Carnauba wax, from the palm tree, or Rice wax, which are more rigid, form a resistant film on the surface of the lashes. Low molecular weight paraffin is also used. Its role is to increase the dry extract in waxes to thicken the makeup, without noticeably affecting its viscosity, which is an essential factor in the coupling between the formulation and the packaging.

The lengthening effect is characterised by a visible increase in the length of the lashes. Film forming polymers such as VP/Eicosene Copolymer are incorporated into the formulation to stretch the product out lengthways on application.

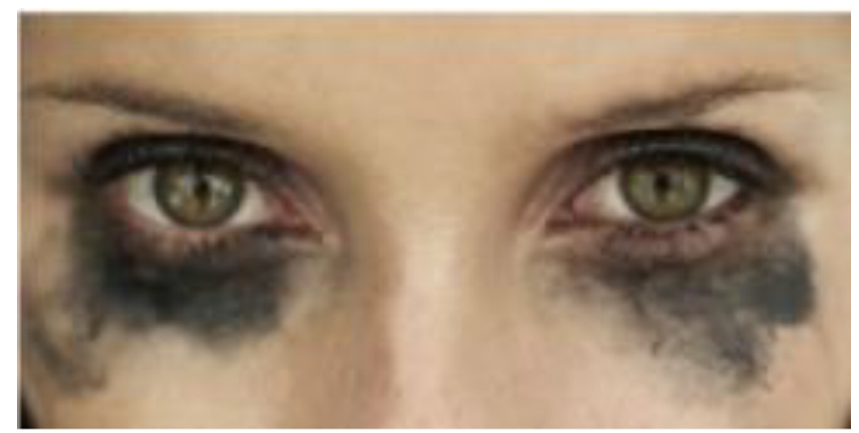

Fig. 11. Extreme smudge-proof effect.

Drying time: There is no oily fat, or very little, because it makes the mascara stick less easily to the lashes and increases drying time.

Smudge-proof and flake-proof properties: A smudgeproof product is made to resist humid and hot atmospheres and sweat or sebum contact. It is also expected to resist cosmetic product contact which creates a lipophilic film. When the product is not efficient regarding this claim, you get the "panda eyes effect", namely a migration of mascara under the eye by partial solubilisation of the formula in sweat and/or sebum (Fig. 11). Water-resistant polymers such as polybutene are important for attaining the smudge-proof effect. VP/Eicosene Copolymer and VP/Hexadecene Copolymer are also good candidates. Polymers can comprise up to $20 \%$ of the formulation, which is essential for validating the smudgeproof property without using a volatile petrochemical solvent.

Fat-soluble polymers ensure that the mascara holds for a long time on the lashes and prevent black flakes from being deposited on the cheeks by preserving the integrity of the film formed. The plasticising properties of polymers and waxes are significant, the aim being that the film deposited on the lashes does not crack when it dries. Beeswax and Paraffin wax have a 


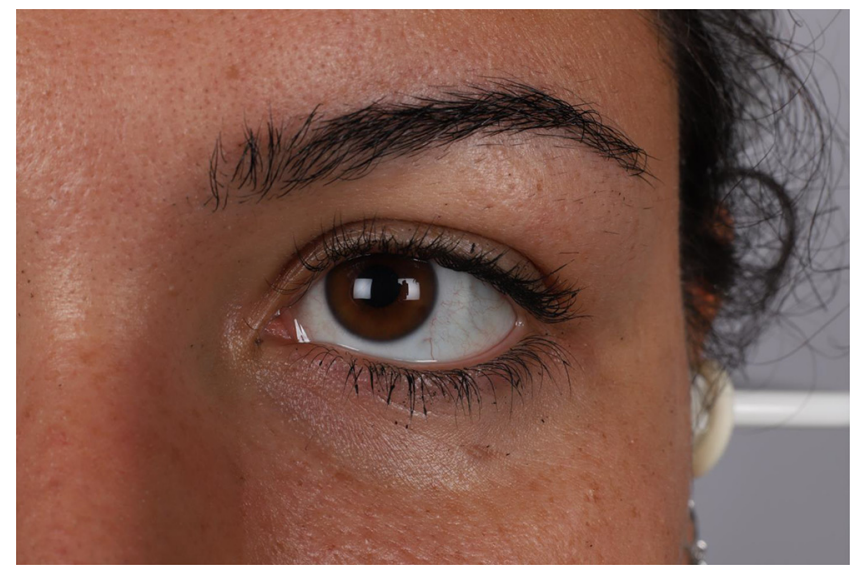

Fig. 12. Photograph of deposits of flakes with a surface area of $+0.55 \mathrm{~mm}^{2}$, the maximum result for validation of the flake-proof property.

good plasticity and help to contribute to the flake-proof property along with the film forming polymers in the formulation. Black pigments need to be prevented from falling onto the cheeks, which would show that the makeup result had not held well over time. The quantity of flakes of mascara that have fallen on the cheeks is evaluated using image analysis. Suppliers that carry out performance measurements consider that a mascara does not achieve the flake-proof property if it deposits flakes on a surface area measuring $+0.55 \mathrm{~mm}^{2}$ of the cheeks and eyelids (Fig. 12). The evaluation is made by comparing the makeup result immediately after application then after $8 \mathrm{~h}$; it is therefore the lasting hold of the mascara which is evaluated through the smudge-proof and flake-proof properties;

\section{Discussion}

The impact of the clean beauty movement on all the properties and claims currently offered by makeup products is not insignificant, far from it. The lipid raw materials that are called into question if a brand wishes to offer a formulation which meets the Clean Beauty criteria are:

All oil-derived raw materials: synthetic waxes, microcrystalline waxes, paraffin waxes, polyethylene waxes, plastic powders, polyethylene powders, hydrocarbon polymers such as Polybutene, and Polyurethane, derivatives of Vinyl Pyrrolidone such as VP/Eicosene Copolymer, volatile solvents such as Isododecane, Isohexadecane, Isoparaffin and Hydrogenated Polyisobutene

All silicone-based raw materials: silicone polymers such as Trimethylsiloxysilicate resin or acrylate silicones such as Acrylates/Stearyl Acrylate/Dimethicone Methacrylate Copolymer, oils of silicone Dimethicone, Caprylyl Methicone, volatile oils of silicone Cyclopentasiloxane, low-viscosity Dimethicone, silicone elastomers such as Dimethicone Vinyl Crosspolymer, silicone surfactants, for example PEG-9 Polydimethylsiloxyethyl Dimethicone or Polyglyceryl-3 Polydimethylsiloxyethyl Dimethicone.
All raw materials derived from polluting manufacturing procedures such as ethoxylated raw materials, with surfactants first in the firing line. In the case of makeup products, siliconebased surfactants such as PEG-9 Polydimethylsiloxyethyl Dimethicone used in foundations are called into question like all ethoxylated surfactants or blended raw materials containing them.

All raw materials that add or generate undesirable impurities in the formulation. Those covered in this text include aminated surfactants such as TEA Stearate used in mascaras, which is a potential generator of nitrosamines.

All raw materials that pose an established or suspected risk to consumers. These include the antioxidant BHT. Formulators are therefore systematically using Tocopheryl Acetate, but it is sometimes too weak to provide good antioxidant protection. Indeed, makeup products contain pigments, some of which are pro-oxidants, such as metallic oxides.

The list of lipid raw materials to be banned could be extended if the constraint of not using genetically modified (GM) raw materials were added. All lecithins and other phospholipids would then become suspect...

Welcome alternatives are arriving from our raw materials suppliers. There are numerous proposals for replacing volatile hydrocarbon solvents, either using undecane \& tridecane (BASF, 2014), C9-C12 alkane (Daito Kasei, 2014) or C14-C19 alkanes (Industries cosmétiques, 2016). Among the nonvolatile carbon-based oils, we are seeing the arrival of polymeric esters such as Ethylhexyl Polyhydroxystearate (Stéarineries Dubois, 2018).

To substitute volatile silicone-based oils, we find C14-C19 alkanes (Seppic, 2020a) and C13-15 alkane (Aprinnova, 2019). For alternatives to silicone-based oils such as Dimethicone or Phenyl Trimethicone, the proposals are very numerous and the chemical natures very diverse. An example is Coco-Caprylate/Caprates (Stéarineries Dubois, 2020), Heptyl Undecylenate (Inolex, 2012), Olive Oil Decyl Esters (and) Squalene (Sophim, 2020), Hydrogenated Rapeseed Alcohol (and) Polyglyceryl-4 Oleate (and) Glyceryl Olivate (Ulprospector, 2020). It is impossible to list everything that is being proposed as the choice is so varied.

There are also rare initiatives for substituting Polybutene proposed by our suppliers. Moreover, they are very effective: Dilinoleic acid/Butanediol copolymer (Biosynthis, 2008) and dimer Dilinoleyl Dimer Dilinoleate (Nippon Fine Chemical, 2018). These 2 esters are, unfortunately, patented for cosmetic applications by a large French cosmetics group, which means it is impossible for the whole of the industry to use them. The other raw materials that could possibly substitute Polybutene include the very sticky Sucrose Acetate Isobutyrate (Eastman, 2020) and Hydrogenated Castor Oil/Sebacic Acid Copolymer (Croda, 2020). There are no proposals for substituting VP derivatives such as VP/Eicosene Copolymer or VP/Hexadecene Copolymer. There is, however, an interesting carbonbased lipophilic gelling agent, which has the advantage of existing in a field in which very few raw materials are being proposed: Castor Oil/IPDI Copolymer \& Caprylic/Capric Triglyceride (Polymer Expert, 2017).

For silicone-based polymers to provide hold, there are no valid propositions for replacing Trimethysiloxysilicate, which 
is essential for achieving long-lasting hold, nor for acrylate silicones. The same applies to silicone elastomers.

Paraffin waxes, synthetic waxes and polyethylene waxes have no adequate substitute either, as plant waxes are very brittle and cause changes in texture over time. Indeed, the shape and size of the crystal's changes over time for natural waxes and their plasticity is significantly lower than that of waxes derived from oil. They absolutely do not play the role of stabiliser or plasticiser.

Polyethylene microbeads, which are so important for the compacting of powders, sensory qualities and for achieving the soft-focus effect in all foundation products, have no substitute. Some microbeads can fulfil one of their functions, but never cover all their performance effects. The lipid beads proposed to replace polyethylene microbeads are Montan and Carnauba wax microbeads, (Micro Powders Inc, 2020), or Glyceryl Behenate microbeads (Gattefossé, 1999). There is no alternative for silicone microbeads such as Vinyl Dimethicone/Methicone Silsesquioxane Crosspolymer.

Silicone surfactants are going to disappear because siliconebased oils are being used less and less in foundations. Formulators are therefore looking for water/oil, naturally sourced, biodegradable surfactants, with contemporary sensory qualities, rendering the product light, fresh and easy-to-apply. A recent initiative in the field of inverse emulsions was proposed by Polyglyceryl-6 Polyhydroxystearate (and) Polyglyceryl-6 Polyricinoleate (Gallon, 2019). Finally, the soap surfactants in mascaras are on their last legs due to the impurities that they generate. No substitute has been proposed by raw materials suppliers, as little is known about these areas of formulation.

Therefore, in the context of "clean beauty", certain claims are more threatened than others, or more difficult to achieve. This affects all cosmetic products and most claims made based on the functional properties of the lipids mentioned above.

\subsection{Lipsticks}

The impact of clean beauty on lipsticks is on the structuring of the stick and on resistance to heat and thermal shocks due to the banning of synthetic waxes.

Hold and non-transfer are two types of performance that are almost impossible to maintain at high levels if volatile hydrocarbon and silicone solvents and hydrocarbon polymers derived from oil chemistry and silicone resin are banned.

\subsection{Powders}

The banning of plastic microbeads and more specifically polyethylene microbeads calls into question the industrial compacting of powders and resistance to breakage, along with good sensory qualities and soft-focus performance.

\subsection{Foundations}

Avoiding silicone surfactants and elastomers weakens the stability of the formulation. The banning of plastic microbeads is a challenge for the soft-focus performance that is so desirable in foundation products. The rejection of silicone-based formulations raises questions as to the feel of the foundations of the future. Claims of hold and non-transfer without silicone polymers such as trimethylsiloxysilicate, volatile silicones or short-chain hydrocarbon solvents are almost impossible to achieve.

\subsection{Mascaras}

The makeup result of mascara is mainly linked to its surfactant. TEA Stearate soaps are disappearing, so volumising and lengthening effects are more complex to obtain. In the same way, the hold of mascara over time, which is evaluated using the smudge-proof and flake-proof properties, is impossible to maintain at the same level. VP/Eicosene Copolymer and VP/Hexadecene copolymer which provide water resistance for the smudge-proof property do not have any substitutes. Plasticising waxes such as Paraffin give suppleness to the film and maintain the integrity of the film on the lashes to prevent flakes from falling onto the face. We therefore need a raw material with a high melting point, which is not polymorphic and is very plastic in its rheological behaviour.

\section{Conclusion}

The cosmetic industry is currently going through a process of change under the influence of the media, as a result of knowledge that has been gained about the environment and increasing awareness in society about the vital need to protect the planet; it is a complicated process, in such a short timescale, to substitute all of the raw materials that need to be replaced while maintaining the same properties. The discussions in the media are moving at a much faster rate than technical progress. It is currently difficult for formulators to respond to the marketing demands for products that meet the criteria of the clean-beauty applications without reducing the overall performance of the makeup. The properties of effectiveness, sensory qualities and stability will not be maintained at the level already achieved until there are substitute raw materials. While waiting for raw materials suppliers to provide new technologies, the current challenges mainly concern stability, sensory qualities and the claim that makeup products have a long-lasting hold.

\section{References}

Abidh S. 2019. The role of lipid composition on the sensory and physical properties of lipsticks. J Am Oil Chem Soc. JAOCS19-0022.

Ajinomoto. 2017. Available from https://www.ajiaminoscience.eu/ images/ASD_Documents/Specialty_Chemicals/Presentation/Aji nomoto_presentation_AmihopeOL.pdf (last consult 2020/20/03).

Aprinnova. 2019. Available from https://aprinnova.com/neossancehemisqualane/ (Last consult 2020/1/04).

BASF. 2014. Available from https://www.carecreations.basf.com/ product-formulations/product-highlights/product-highlights-de tail/CETIOL-ULTIMATE/30597825 (Last consult 2020/1/04).

Biosynthis. 2008. Available from https://www.biosynthis.com/visco plast (Last consult 2020/01/04).

Bonnet C. 2018. Lipids, a natural raw material at the heart of cosmetics innovations. OCL 25(5): D501.

Croda. 2020. Available from https://www.crodapersonalcare.com/engb/products-and-applications/product-finder/product/1964/Croda bond_1_CSA (Last consult 2020/10/04). 
Daito Kasei. 2014. Available from https:/www.daitokasei.com/upload/ product/file/file_en00000271.pdf (Last consult 2020/1/04).

De Carames M. 1978. Development of a lipstick base. Cosmet Toil 93: 15.

de Clermont-Gallerande H. 2001. Formulation et étude physicochimique d'un rouge à lèvres solide, transparent et amorphe. Thèse de Doctorat, NNT: 2001AIX30016.

de Clermont-Gallerande H, Chavardes V, Zastrow L. 1999. Crystal clear transparent lipstick based on solidified oils. Int J Cosmet Sci 21(6): 413-24. https://doi.org/10.1046/j.1467-2494.1999.211909.x.

de Clermont-Gallerande H, Barre A, Snabre P. 2014. Ageing and stability of loose powdered cosmetic preparations: Influence upon compaction and fracture resistance of pressed tablets. Procedures of 28th IFSCC Congress Paris.

de Clermont-Gallerande H, Abidh S, Lauer A, Severine N, Cuvelier G, Delarue J. 2018. Relations between the sensory properties and fat ingredients of lipsticks. OCL 25(5): D502.

Department of Consumer and Veterinary Affairs. 2017. Substances cancérigènes dans les cosmétiques pour les yeux. Département de la Sécurité, de l'Emploi et de la Santé (DSES). Available from https://www.ge.ch/actualite/substances-cancerigenes-cosme tiques-yeux-5-04-2017.

Douguet M, Picard C, Savary G, Merlaud F, Loubat-Bouleuc N, Grisel M. 2017. Spreading properties of cosmetic emollients: Use of synthetic skin surface to elucidate structural effect. J Coll Surf, Elsevier, 154: 307. https://doi.org/10.1016/j.sol surfb.2017.03.028.

Drew RC. 1978. Evaluation of mechanical stresses set up in lipsticks during application. J Soc Cosmet Chem 29: 441.

Dweck AC. 1981. The sweating of lipsticks. Cosm Toiletr 96: 29.

Eastman. 2020. Available from https://www.eastman.com/Pages/ ProductHome. aspx?product=71001070 (Last consult 2020/10/04).

Fioleau H, Granvuinet C, de Clermont-Gallerande H. 2015. Color impact of pigment wetting ingredients on compact powder composition. Procedures of XI Conferenza Del Colore, Gruppo Del Colore, Milano. Available from https:/gruppodelcolore.org/ wp-content/uploads/2015/01/Colour_and_Colorimetry_VOLXI B_ENG_REV4.pdf (last consult 2020/25/03).

Gallon V. 2019. Available from https://www.premiumbeautynews. $\mathrm{com} / \mathrm{fr} /$ gattefosse-un-emulsionnant-naturel,14882 (Last consult 2020/1/04).

Gattefossé. 1999. Available from https:/www.gattefosse.com/fr/phar maceuticals-products/compritol-888-ato (Last consult 2020/10/04).

Goodsitt L. 2019. The future of color cosmetics. Global annual review: what's now and what's next for the colour cosmetics market. Available from https://clients.mintel.com/report/the-fu ture-of-colour-cosmetics-2019? fromSearch=\%3Ffilters.category \%3D2\%26last_filter\%3Dcategory (last consult: 2020/20/03).

Humbert F. 2013. Cosmétiques et perturbateurs endocriniens. Available from https://www.quechoisir.org/enquete-cosme tiques-et-perturbateurs-endocriniens-66-produits-analysesn4839/ (last consult: 2020/28/05).

Industries cosmétiques. 2016. Available from https://www.industriescosmetiques.fr/seppic-lance-deux-gammes-demollients-emos mart-et-emogreen/ (Last consult 2020/1/04).

Inolex. 2012. Available from https://inolex.com/pc/Products/Sili cone-Alternatives (Last consult 2020/01/04).
Kermarec A. 2011. Exsudation et rhéophysique des matériaux hétérogènes solide/liquide à base de corps gras. Thèse de Doctorat, NNT: 2011BOR14327.

Le Mélinaire F. 2019. Clean Beauty? Vers plus de transparence dans les cosmétiques? Available from https://www.cosmopolitan.fr/ clean-beauty-vers-plus-de-transparence-dans-les-cosme tiques,2027449.asp (last consult: 2020/28/05).

Loubat-Bouleuc N. 2004. Les esters en cosmétologie : généralités et fonctionnalités. OCL 11(6): 454-456.

Micro Powders, Inc. 2020. Available from http://www.mpipersonalcare. com/ViewProducts.aspx?id=10\&fp=main (Last consult 2020/10/04).

Moyou E. 2018. Critères pris en compte lors de l'achat de produits de beauté en France 2017. Available from https://fr.statista.com/ statistiques/797254/criteres-achat-produits-cosmetiquesfemmes-france/ (last consult: 2020/26/02).

Nandkishor K, Nere NK, Diwan M, et al. Case studies on crystallization scale-up. In: Chemical Engineering in the Pharmaceutical Industry: Active Pharmaceutical Ingredients, Ende ed., 2019.

Nipponseika Chemical. 2018. Available from https://www.nippon seika-cosme.com/english/products/product-detail.html?c= c789412laufjw6qkhl6ew322g995s (Last consult 2020/10/04).

Official Journal of the European Union. 2009. Annex 3 of the Regulation (EC) $\mathrm{N}^{\circ} \mathrm{N}^{\circ} 1223 / 2009$ of the European Parliament and of the Council of 30 November 2009 on cosmetic products. L 352/ 59-209. Available from https://eur-lex.europa.eu/LexUriServ/ LexUriServ.do?uri=OJ:L:2009:342:0059:0209:fr:PDF.

Oshimura E. 2016. Une poudre blanche maqique du formulateur: le Lauroyl Lysine. Available from https://cosmeticobs.com/fr/ articles/ingredients-50/une-poudre-blanche-magique-du-formula teurnbsp-le-lauroyl-lysine-3674 (last consult 2020/20/03).

Pietsch W. 2002. Agglomeration Processes - Phenomena, Technologies, Equipment, Wiley-VCH, Verlag GmbH.

Polymer Expert. 2017. Available from https://www.polymerexpert.fr/ produits/estogel/estogel-m/ (Last consult 2020/10/04).

Seppic. 2020a. Available from https://www.seppic.com/fr/sil-etaitpossible-remplacer-silicones (Last consult 2020/1/04).

Seppic. 2020b. Available from https://www.seppic.com/fr/lipacide-ug (last consult 2020/22/03).

Snabre P, Habouzit D. 2013. Chauffage, endommagement et exsudation des matériaux semi-cristallins à base de corps gras. I-Revues, 21 ${ }^{e}$ Congrès français de Mécanique [CFM2013], colloques thématiques, C10-Rencontres Physiques-Mécaniques.

Sophim. 2020. Available from https://www.sophim.com/fr/substitutssilicone/ (Last consult 2020/01/04).

Stéarineries Dubois. 2018. Available from https://www.stearineriedubois.com/2018/04/dub-estoline-to-be-launched-at-in-cosmet ics-2018/ (Last consult 2020/1/04).

Stéarineries Dubois. 2020. Available from https://www.stearinerie-dubois. com/secteurs-dactivites/cosmetique/ (Last consult 2020/1/04).

Tita-Goldstein A. 2013. Mise en forme des poudres par compression : influence du procédé et de la formulation pour la maîtrise des propriétés d'usage. Thèse de Doctorat, NNT: 2013LOR R0238.

Ulprospector. 2020. Available from https://www.ulprospector.com/ en/asia/PersonalCare/Detail/101883/1012482/GILSOLIDE-V (Last consult 2020/01/04).

Weckerle. 2020. Available from https://www.weckerle.com/ machines/machine/mpl/?lang=fr (last consult 2020/20/03).

Cite this article as: de Clermont-Gallerande H. 2020. Functional roles of lipids in make-up products. OCL 27: 33. 